\title{
Romania's urban policy in the context of COVID-19 pandemic time
}

\author{
Daniela Antonescu \\ Institute of National Economy, Romanian Academy, 13, 13 September Street, 050711 Bucharest, Romania; \\ daniela.antonescu25@gmail.com
}

Received: 16 November 2021; Revised: 19 December 2021; Accepted: 21 December 2021;

Published online: 24 December 2021

\begin{abstract}
Under the conditions of frequent changes, of some edifying transformations and perpetual challenges, urban policy undergoes changes/adjustments/updates over certain time intervals. These changes generate increasingly more complex requirements that impose drafting a flexible multidisciplinary framework able to support the future development of a territory. In full debate-process, the new urban policy of Romania promotes sustainability, resilience and inclusive growth, on the background of a critical period under the dominance of the SARS-CoV2 pandemic. This new policy brings around the discussion table experts from relevant fields: decision factors, urbanists, economists, architects, citizens, civic initiative groups, etc. The national urban policy must address all categories of urban areas (defined as a city area considered as the inner city plus built-up environs, irrespective of local body administrative boundaries), being fundamental in implementing the goals set by the New EU Urban Agenda, approved in the framework of the Habitat III conference of the United Nations (2016) and the new provisions of the New Leipzig Charter (2020). Urban policy must ensure a single planning framework that would support the implementation of the programs and projects financed from European and national funds, preparing thus the financial exercise 2021-2027. Considering the above mentioned, the present paper aims to review the important and strategic elements of the future urban policy from Romania and its role in promoting and supporting balanced territorial development under the conditions of the SARS-CoV2 pandemic crisis which is far from over.
\end{abstract}

Key words: urban policy, regional development, territorial resilience, social cohesion, COVID-19 crisis

Citation: Antonescu, D. (2021). Romania's urban policy in the context of COVID-19 pandemic time. Central European Journal of Geography and Sustainable Development, 3(2), 85-102. https://doi.org/10.47246/CEJGSD.2021.3.2.6

https://doi.org/10.47246/CEJGSD.2021.3.2.6

| Full text | 